six periods lasting 4 to 5 days, the last one being just a few days before admission.

On examination she was drowsy with an oral temperature of $35.8^{\circ} \mathrm{C}$, skin pallor and no pubic or axillary hair. The blood pressure was $120 / 70 \mathrm{mmHg}$ recumbent, $110 / 80 \mathrm{mmHg}$ standing and the fundi and visual fields were normal.

Investigations revealed: plasma sodium 112 $\mathrm{mmol} / \mathrm{l}$, potassium $3.9 \mathrm{mmol} / \mathrm{l}$, bicarbonate 22 $\mathrm{mmol} / \mathrm{l}$, urea $2 \mathrm{mmol} / \mathrm{l}$, osmolality $230 \mathrm{mOsm} / \mathrm{kg}$. 9 a.m. plasma cortisol was $75 \mathrm{nmol} / 1$ (normal range 165-700) and rose to $420 \mathrm{nmol} / 1$ after a short tetracosactrin test. Fasting (9.0 a.m.) plasma adrenocorticotrophin (ACTH) was less than $5 \mathrm{ng} / \mathrm{l}$ (normal $<10-80$ ). After a 3-day ACTH stimulation test the plasma cortisol level was $1033 \mathrm{nmol} / \mathrm{l}$ (normal range), results which demonstrated secondary adrenal failure.

Her symptoms rapidly improved following treatment with intravenous hydrocortisone and saline, and the electrolyte abnormalities reverted to normal. Serum total thyroxine was $102 \mathrm{nmol} / 1$ (normal range, 55-155) but there was no rise in serum thyroid stimulating hormone (TSH) following intravenous injection of $200 \mu \mathrm{g}$ of thyrotrophin releasing hormone (TRH). An insulin tolerance test failed to produce any rise in plasma cortisol, whilst growth hormone rose from $1.2 \mathrm{mu}$./1 to only $2.7 \mathrm{mu}$./ at thirty minutes despite adequate hypoglycaemia. The serum levels of follicle stimulating hormone (FSH) and luteinising hormone ( $\mathrm{LH})$ were $5 \cdot 2 \mathrm{u} . / 1$ and $3 \cdot 2$ u./l respectively, which are consistent with intact ovarian function.

Nine months after her last menstrual period, which had been just before admission, serum FSH and LH were $3.4 \mathrm{u} . / 1$ and $2.6 \mathrm{u} . / 1$ respectively, which are low for post-menopausal women (normal post-menopausal levels $30-120$ and 17-45 u./l respectively). Serum prolactin concentration was $160 \mathrm{mu}$./l (normal, 40-445). Serum thyroxine was $64 \mathrm{nmol} / \mathrm{l}$ and a further TRH test gave no TSH response.

No cause for her hypopituitarism has been found, chest X-ray, pituitary fossa tomography, perimetry and auto-immune serology tests being normal. Recently (1977) she developed iron deficiency anaemia, and was found to have a gastric ulcer.

\section{Discussion}

This patient now has panhypopituitarism of unknown aetiology. However, at the time of presentation in pituitary coma, gonadotrophin function appeared intact, with regular two-monthly menstrual periods. The picture at that time was one of severe hyponatraemia, and the presence of menstruation was thought to make the diagnosis of panhypopituitarism unlikely. However this proved not to be the case.

The only pointer to pituitary disease was absence of body hair associated with pallor of the skin. Continuing menstruation with pituitary coma must be a rare occurrence as a literature search has failed to find similar case reports.

\section{References}

HALL, R. (1974) Fundamentals of Clinical Endocrinology, 2nd edn, p. 25. Pitman Medical, London.

Simpson, S.L. (1959) Major Endocrine Disorders, 3rd edn, pp. 56 and 62. Oxford University Press.

SheehaN, H.L. (1939) Simmonds disease due to postpartum necrosis of the anterior pituitary. Quarterly Journal of Medicine, 8, 277.

\title{
Normal alkaline phosphatase in primary biliary cirrhosis
}

\author{
DAVID LESLIE \\ M.B., M.R.C.P. \\ Westminster Hospital, London SWI 2AP
}

\begin{abstract}
Summary
A patient with primary biliary cirrhosis is described. Throughout her illness the serum alkaline phosphatase remained normal and this unique feature emphasizes the importance of histology in diagnosing the disease.

\section{Introduction}

Primary biliary cirrhosis (PBC) is associated with
\end{abstract}

a raised serum alkaline phosphatase level (Sherlock and Scheuer, 1973). A patient is described in whom the level of this enzyme remained normal throughout her long illness.

\section{Case report}

A Caucasian patient presented in 1963 at the age of 56 years with a transient episode of tiredness and 


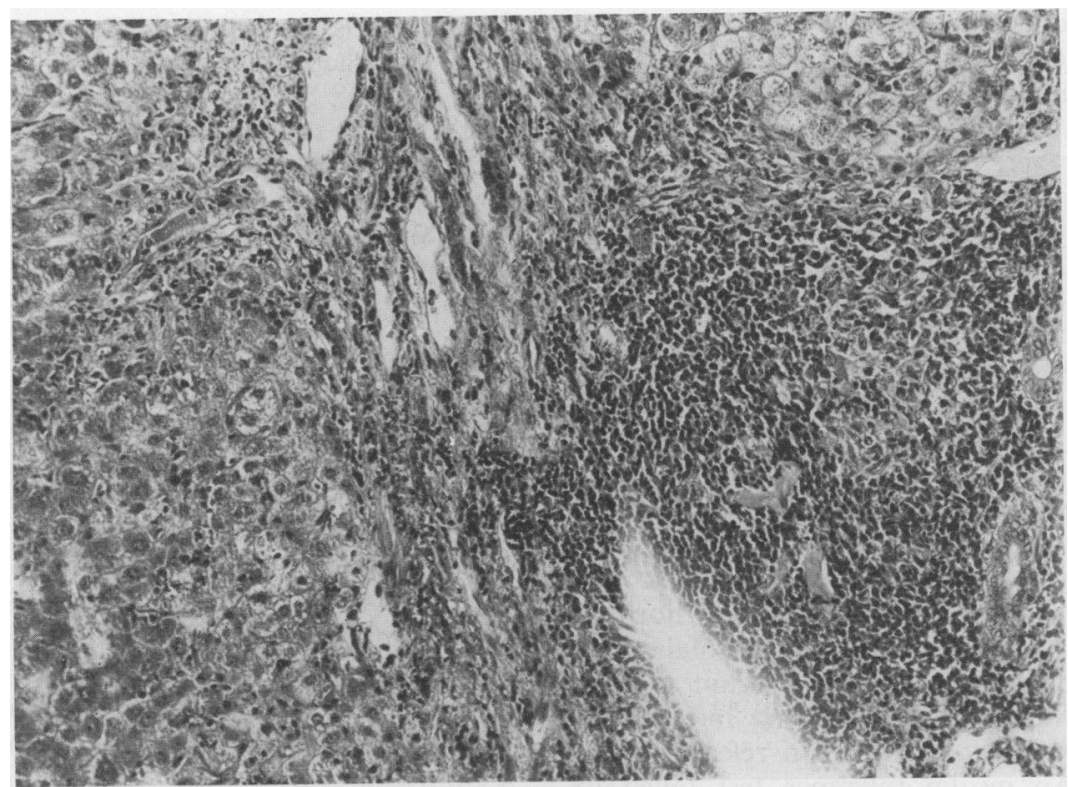

FIG. 1. Periportal inflammation with granuloma and bile-duct proliferation $(\mathrm{HE}, \times 160)$.

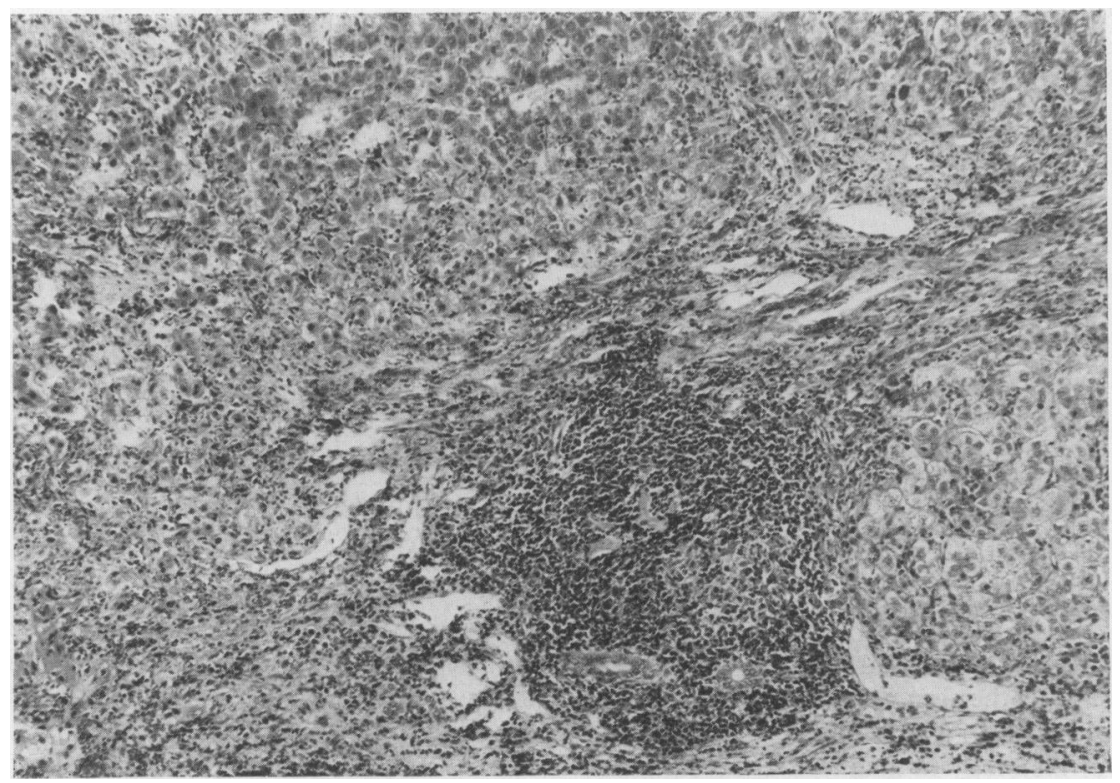

FIG. 2. Portal inflammation with granuloma and bile-duct proliferation (HE, $\times 100)$. 
was found to have hepatosplenomegaly which had first been noted in 1958. A liver biopsy showed the pathognomonic features of PBC with bile-duct destruction, proliferation of the bile ductules, granulomata and an inflammatory cell reaction (Scheuer, 1967) (Figs 1 and 2). At that time the total bilirubin was $9 \mu \mathrm{mol} / 1$, alkaline phosphatase $8 \mathrm{KAu} . / 100 \mathrm{ml}$ (upper normal limit $17 \mathrm{KAu}$.), alanine aminotransferase $95 \mathrm{u}$. (normal range, 4-17 u.), aspartate aminotransferase $168 \mathrm{u}$. (normal range 3-12 u.), IgM $2.8 \mathrm{~g} / 1$ (normal range $0 \cdot 3-2.0 \mathrm{~g} / \mathrm{l}$ ), mitochondrial antibodies were present in a titre $>1 / 1280$, positive bile canaliculi antibodies, negative smooth muscle antibodies and negative hepatitis-associated antigen. A wedge biopsy performed at laparotomy confirmed the diagnosis of PBC.

She remained well until 1970 when she developed diabetes mellitus and pancytopenia with a hypercellular bone marrow ascribed to hypersplenism. In 1975 she was admitted with ascites. At that time she was deeply pigmented but anicteric and without pruritus. A repeat liver biopsy showed progression of her PBC to a stage 4 cirrhosis (Scheuer, 1967). She responded to diuretics, but in 1976 she was readmitted with a haematemesis and died. Although a barium swallow had shown oesophageal varices, the cause of her haematemesis was not determined and no post-mortem examination was allowed.

Her alkaline phosphatase and 5-nucleotidase levels remained normal throughout her illness. Thus the alkaline phosphatase was $8 \mathrm{KAu}$. in 1963, 8 in 1967, 14 in 1970, 8 in 1975 and $11 \mathrm{KAu}$. in 1976. On electrophoresis the alkaline phosphatase was predominantly of hepatic origin with a minor component showing the mobility of the bone isoenzyme.

\section{Discussion}

This case has several unusual features. Despite evidence of progressive disease she had a prolonged survival without jaundice or pruritus. Zeegen et al., (1969) found that patients can develop PBC and portal hypertension without the classical symptoms of PBC. However, the alkaline phosphatase was raised in every case.

It has been postulated (Schaffner, 1975) that the raised alkaline phosphatase is due to bile regurgitation into the portal tract tissues through damaged ducts. In their review, Sherlock and Scheuer (1973) reported just two patients, both discovered incidentally, who had an initial alkaline phosphatase of less than $20 \mathrm{KAu}$., but no follow-up was recorded.

The present patient had a persistently normal alkaline phosphatase until her death and is believed to be the first such case reported. This underlines the lack of specificity of biochemical tests and, while histology is often not diagnostic (Scheuer, 1967), it emphasizes its value in diagnosing the disease.

\section{Acknowledgments}

I thank Dr R. I. S. Bayliss for permission to report this case and Professor Peter Scheuer for reviewing the histology.

\section{References}

SCHAFfner, F. (1975) Primary biliary cirrhosis. Clinics in Gastroenterology, 4, 351.

Sherlock, S. \& Scheuer, P.J. (1973) The presentation and diagnosis of 100 patients with primary biliary cirrhosis. New England Journal of Medicine, 289, 674.

SCHeuer, P.J. (1967) Primary biliary cirrhosis. Proceedings of the Royal Society of Medicine, 60, 1257.

Zeegen, R., Stansfield, A.G., Dawson, A.M. \& Hunt, A.H. (1969) Bleeding oesophageal varices as the presenting feature in primary biliary cirrhosis. Lancet, ii, 9 .

\title{
Gastro-colic fistula secondary to benign gastric ulceration
}

\author{
ROY TAYLOR \\ M.B., Ch.B., B.Sc. (Hons.) \\ Royal Infirmary, Edinburgh
}

\begin{abstract}
Summary
An 80-year-old woman developed osteoarthritis of the knees as a complication of her obesity. Indomethacin treatment precipitated gastric ulceration, which led to the formation of a gastro-colic fistula.
\end{abstract}

GASTRO-COLIC fistula is a rare condition and, unlike gastro-jejuno-colic fistula which usually occurs secondary to partial gastrectomy, is most often a complication of invasive gastric or colonic carcinoma (Cody et al., 1975). Other possible causes include 